\title{
Electroconductive and Dielectric Properties of Composites Based on Bismuth Vanadate
}

\author{
J.N. Torba ${ }^{a}$, N.V. Golubko ${ }^{a}$, E.A. Fortalnova ${ }^{a, b}$, G.M. Kaleva $^{a}$, M.G. Safronenko $^{b}$, \\ N.U. VenskovskiI ${ }^{b}$ And E.D. POlitova ${ }^{a, *}$ \\ ${ }^{a}$ Karpov Institute of Physical Chemistry, Vorontsovo Pole St., 10, 105064, Moscow, Russia \\ ${ }^{b}$ Peoples' Friendship University of Russia, Ordzhonikidze St., 3, 117198, Moscow, Russia \\ Ceramic composites $(100-n) \mathrm{Bi}_{4} \mathrm{~V}_{2} \mathrm{O}_{11-z}-n \mathrm{Ce}_{0.9} \mathrm{Gd}_{0.1} \mathrm{O}_{1.9}$ with $n=0 \div 25$ wt\% were prepared and studied \\ by the X-ray diffraction, dielectric spectroscopy, and impedance methods. Slight increase in the unit cell volume \\ accompanied by monotonous decrease in temperatures and broadening of the $\alpha-\beta$ and $\beta-\gamma$ phase transitions with \\ increasing fluorite content was observed in the composites studied. Increase in melting temperatures of composites \\ with $n \geq 10$ with the retention of their high ionic conductivity was also proved.
}

PACS numbers: 72.80.Tm, 77.22.Ch, 72.20.-i, 61.72.-y

\section{Introduction}

Bismuth vanadate $\mathrm{Bi}_{4} \mathrm{~V}_{2} \mathrm{O}_{11-z}$ (BIVOX) attracts much attention due to its very high ionic conductivity $(\approx 0.02 \mathrm{~S} / \mathrm{cm})$ at temperatures $<1000 \mathrm{~K}[1]$. However, application of the bismuth vanadate-based materials is hindered by their poor thermodynamic stability in reducing atmospheres. The parent bismuth vanadate is characterized by first order phase transitions between $\alpha$ and $\beta$ polymorphous modifications at temperatures $\approx 700 \mathrm{~K}$ and between $\beta$-phase and highly conducting tetragonal $\gamma$-phase at temperatures $\approx 850 \mathrm{~K}[2,3]$.

It is well known that variation of the microstructure in composites based on solid electrolytes may ensure enhancement of their density and functional properties due to modification of grain boundary properties. It was also shown that electrical properties of ceramics can be strongly dependent on their microstructure, and for samples with larger grains, lower conductivity was reported $[4,5]$.

In this work, composites in the system composed of bismuth vanadate and fluorite structure compound were studied. As a fluorite structure compound, highly dispersed $\mathrm{Ce}_{0.9} \mathrm{Gd}_{0.1} \mathrm{O}_{1.9}$ was chosen. Gadolinium doped ceria has been reported to have the highest ionic conductivity among ceria-based oxides. This composition is a potential candidate for use as the electrolyte for applications in intermediate temperature solid oxide fuel cells [6]. Sintering temperature for ceria-based oxides is rather high $(>1600 \mathrm{~K})$. Therefore, it is expected that addition of this oxide may provide an enhancement of the

* corresponding author; e-mail: politova@cc.nifhi.ac.ru temperature stability of the BIVOX-based composites. As a rule, solid solutions are not formed in mixtures of oxides with perovskite and fluorite structures. So, high ionic conductivity retention is also expected.

\section{Experimental procedure}

$\mathrm{Bi}_{4} \mathrm{~V}_{2} \mathrm{O}_{11-z}$ powder was prepared by the solid state reaction method, starting from preliminary dried initial oxides $\mathrm{Bi}_{2} \mathrm{O}_{3}(99.9 \%)$ and $\mathrm{V}_{2} \mathrm{O}_{5}(99.99 \%)$. Highly dispersed $\mathrm{Ce}_{0.9} \mathrm{Gd}_{0.1} \mathrm{O}_{1.9}$ was prepared by the coprecipitation method starting from corresponding hydroxides and annealed at $870 \mathrm{~K}$ before sintering. Ceramic composites $(100-n) \mathrm{Bi}_{4} \mathrm{~V}_{2} \mathrm{O}_{11-z^{-}}-\mathrm{Ce}_{0.9} \mathrm{Gd}_{0.1} \mathrm{O}_{1.9}$ with $n=0,5,10$, $15,20,25 \mathrm{wt} \%$ were prepared by sintering pressed pellets at $1073 \mathrm{~K}(n=0)$, and $1123 \mathrm{~K}(n \geq 5)(8 \mathrm{~h})$ followed by slow cooling. It was revealed that melting temperature $T_{\mathrm{m}}$ of the samples with $n \geq 10$ increases to $>100 \mathrm{~K}$ in comparison to the $T_{\mathrm{m}}$ value of $\mathrm{Bi}_{4} \mathrm{~V}_{2} \mathrm{O}_{11-z}\left(T_{\mathrm{m}}=1108 \mathrm{~K}\right.$ according to differential thermal analysis (DTA) data). The samples prepared were analyzed using the X-ray diffraction (DRON-3, Cu $K_{\alpha}$ radiation), DTA, dielectric spectroscopy and impedance methods in the temperature interval of 300-950 K at frequencies of $60 \mathrm{~Hz}-1 \mathrm{MHz}$ (Agilent 4284 A LCR meter, $1 \mathrm{~V}$ ). To provide electrical contacts, flat surfaces of the samples used in electrical measurements were coated with $\mathrm{Pt}$-containing paste and fired at $973 \mathrm{~K}$.

\section{Results and discussion}

According to X-ray data, the composites, containing orthorhombic $\alpha$-phase $\mathrm{Bi}_{4} \mathrm{~V}_{2} \mathrm{O}_{11-z}$ and fluorite phase $\mathrm{Ce}_{0.9} \mathrm{Gd}_{0.1} \mathrm{O}_{1.9}$, are formed in all samples (Fig. 1). 


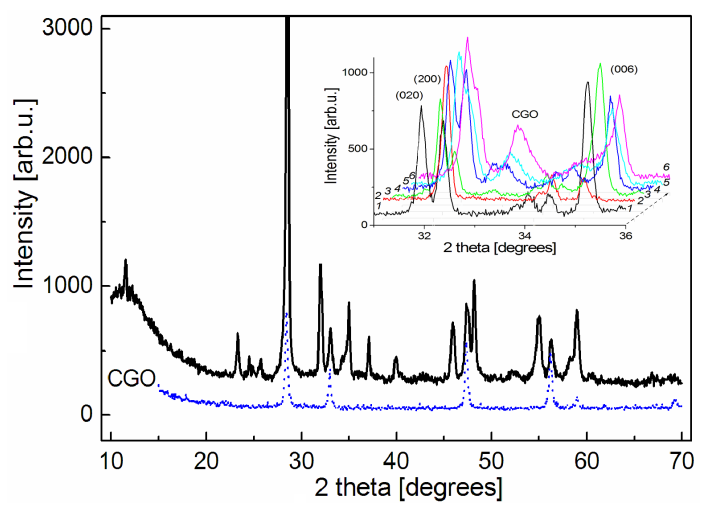

Fig. 1. The X-ray diffraction pattern of the composite ceramic sample $75 \mathrm{wt} \% \mathrm{Bi}_{4} \mathrm{~V}_{2} \mathrm{O}_{11-z}-25 \mathrm{wt} \%$ $\mathrm{Ce}_{0.9} \mathrm{Gd}_{0.1} \mathrm{O}_{2-z}$. In the inset, parts of the X-ray diffraction patterns of the composites $(100-n) \mathrm{Bi}_{4} \mathrm{~V}_{2} \mathrm{O}_{11-z^{-}}-n$ $\mathrm{Ce}_{0.9} \mathrm{Gd}_{0.1} \mathrm{O}_{2-z}$ with $n=0$ (1), 5 (2), 10 (3), 15 (4), 20 (5), 25 (6) are shown.

The unit cell parameter $b$ remains constant while the unit cell parameters $a, c$, and $\mathrm{V}$ increase slightly with increasing the fluorite content (Fig. 2). This may point to slight reduction of $\mathrm{V}^{5+}$ cations to $\mathrm{V}^{4+}$. The unit cell parameter of the fluorite constituent remains practically unchanged (Fig. 1, inset).

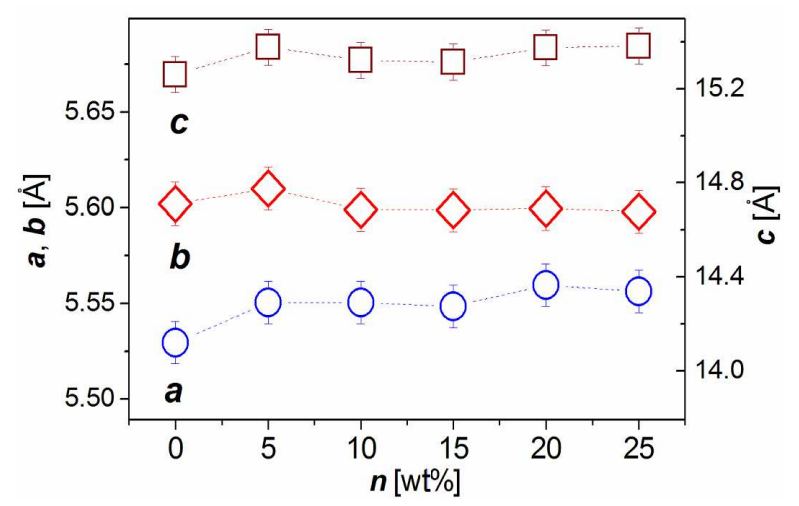

Fig. 2. Concentration dependences of the unit cell parameters $a, b, c$ for composites $(100-n) \mathrm{Bi}_{4} \mathrm{~V}_{2} \mathrm{O}_{11-z^{-}}$ $n \mathrm{Ce}_{0.9} \mathrm{Gd}_{0.1} \mathrm{O}_{2-z}$.

In the dielectric permittivity versus temperature plots $\varepsilon(t)$ and dielectric loss versus temperature plots $\tan \delta(t)$, peaks, corresponding to both the ferroelectric-paraelectric $\alpha-\beta$ and $\beta-\gamma$ phase transitions, were observed in all composites (Fig. 3, 4a,c). The temperature hysteresis of $\beta-\gamma$ phase transition lies within $6-15 \mathrm{~K}$ while that of $\alpha-\beta$ phase transition increases drastically from $76 \mathrm{~K}(n=0)$ up to $\approx 200 \mathrm{~K}(n=20)$. Large hysteresis values make it rather difficult to determine temperature of phase transitions from the $\varepsilon(t)$ curves. Therefore, they were obtained from the temperature derivatives of dielectric permittivity versus temperature curves. A monotonous decrease in temperatures of both $\alpha-\beta$ and $\beta-\gamma$ phase transitions from $715 \mathrm{~K}$ to $690 \mathrm{~K}$ and from 815 to $750 \mathrm{~K}$, respectively, with increasing $n$ was observed in the composites studied.

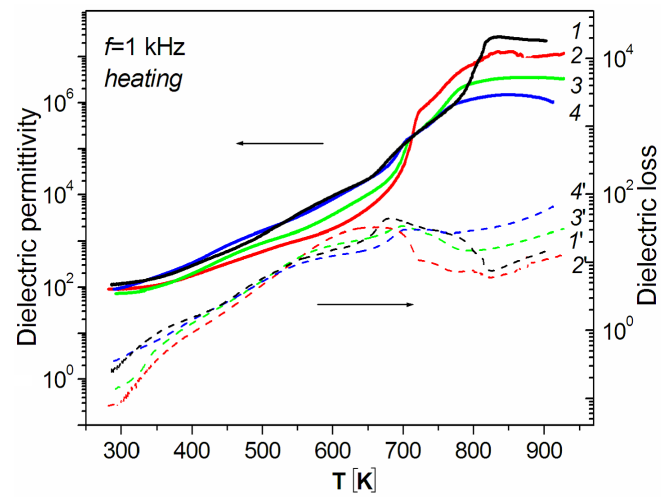

Fig. 3. Dielectric permittivity (solid) and dielectric loss (dash) versus temperature curves for composites $(100-n) \mathrm{Bi}_{4} \mathrm{~V}_{2} \mathrm{O}_{11-z}-n \mathrm{Ce}_{0.9} \mathrm{Gd}_{0.1} \mathrm{O}_{2-z}$ with $n=0$ (1), 5 (2), 10 (3), 15 (4) measured on heating at the frequency of $f=1 \mathrm{kHz}$.
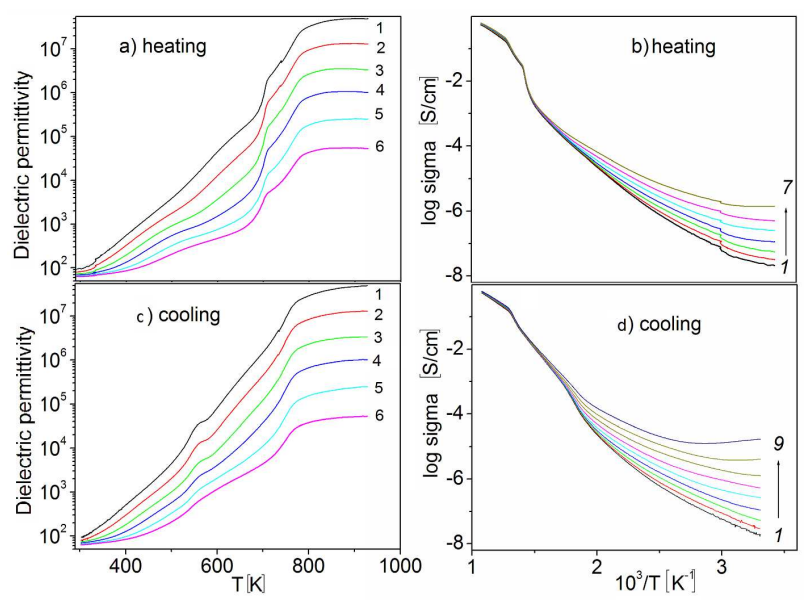

Fig. 4. Dielectric permittivity versus temperature curves (a), (c) and total conductivity versus temperature curves (b), (d) for composites $(100-n)$ $\mathrm{Bi}_{4} \mathrm{~V}_{2} \mathrm{O}_{11-z}-n \mathrm{Ce}_{0.9} \mathrm{Gd}_{0.1} \mathrm{O}_{2-z}$ with $n=10$ measured on heating (a), (b) and cooling (c), (d) at frequencies $100 \mathrm{~Hz}($ (1), $300 \mathrm{~Hz}$ (2), $1 \mathrm{kHz}$ (3), $3 \mathrm{kHz}$ (4), $10 \mathrm{kHz}$ (5), $30 \mathrm{kHz}(6), 100 \mathrm{kHz}(7), 300 \mathrm{kHz}(8), 1 \mathrm{MHz}(9)$.

In the total conductivity versus reciprocal temperature curves, anomalies, corresponding to both $\alpha-\beta$ and $\beta-\gamma$ phase transitions, were also observed (Fig. 4b,d).

Additionally, broadening of phase transitions and retention of total conductivity of the samples at the level of $\approx 0.04-0.05 \mathrm{~S} / \mathrm{cm}$ was observed in compositions with $n=0-15$ at temperatures as high as $\approx 900 \mathrm{~K}$. 


\section{Conclusion}

Composites $(100-n) \mathrm{Bi}_{4} \mathrm{~V}_{2} \mathrm{O}_{11-z}-n \mathrm{Ce}_{0.9} \mathrm{Gd}_{0.1} \mathrm{O}_{1.9}$ have been prepared. A slight increase in the unit cell volume of the bismuth vanadate constituent accompanied by a decrease in $\alpha-\beta$ and $\beta-\gamma$ phase transition temperatures has been observed. Increase in melting temperatures of composites with $n \geq 10$ allows us to expect enhancement of temperature stability of composites with the retention of their high ionic conductivity.

\section{Acknowledgments}

The work was supported by the Russian Foundation for Basic Research (grant 07-03-00133).

\section{References}

[1] I. Abrahams, J.C. Boivin, G. Mairesse, G. Nowogrocki, Solid State Ionics 40/41, 934 (1990).

[2] J.C. Boivin, C. Pirovano, G. Novogrocki, G. Mairesse, $\mathrm{Ph}$. Labrune, G. Lagrange, Solid State Ionics 113-115, 639 (1998).

[3] G. Mairesse, P. Roussel, R.N. Vannier, M. Anne, C. Pirovano, G. Novogrocki, Solid State Sci. 5, 851 (2003).

[4] C. Pirovano, M.C. Steil, E. Capoen, G. Novogrocki, R.N. Vannier, Solid State Ionics 176, 2079 (2005).

[5] J.R. Dygas, M. Malys, F. Krok, W. Wrobel, A. Kozanecka, I. Abrahams, Solid State Ionics 176, 2085 (2005).

[6] S. Ramesh, C. Vishnuvardhan Reddy, Acta Phys. Pol. A 115, 909 (2009). 